INTERNATIONAL DESIGN CONFERENCE - DESIGN 2018

https://doi.org/10.21278/idc.2018.0423

\title{
MEET AURA: A STUDY ON HOW ITERATIVE DESIGN METHODOLOGIES AND USER PARTICIPATION HELP IMPROVE RESULTS IN TECHNOLOGY DRIVEN PILOT PROJECTS
}

\author{
M. Pérez García and S. Saffón López
}

\begin{abstract}
Design is an essential aspect of developing successful products and services in technology-driven scenarios. This study emphasizes on exploring how iterative design methodologies and user participation in service design can help shape a better user experience and maximise learnings when working on technology-driven pilot projects. This research study will focus on a pilot project called Meet Aura involving Artificial Intelligence, cognitive capabilities and multi-interface interaction. It specifically seeks to generate a conceptual framework that can be replicated in future pilot projects.
\end{abstract}

Keywords: artificial intelligence (AI), design methodology, service oriented design, technology development, innovation

\section{Introduction}

There are lots of design approaches and methods (Kumar, 2012) that are applied to physical products, and over the last ten years, many of them have shifted towards services, such as customer journeys, mapping, interviews, shadowing (Merholz et al., 2008; Stickdorn, 2009; Patricio et al., 2011). However, when it comes to projects dealing with Artificial Intelligence (AI) and new ways of interacting with users, such as voice interaction, design innovation approaches are still a rather unexplored territory. In fact, what it is often left unsaid is design's interplay between multidisciplinary teams and users on breakthrough innovations.

For a service design team in a technology organisation, it becomes very important to identify, use and assess new design methods and processes that can help address the highly uncertain challenges that user centred design for digital services faces almost daily. When it comes to AI, voice interaction, virtual assistants, machine learning, and so forth, there is still a lack of best practices in product and service design regarding design methods in technology-driven projects in the telecoms sector. Therefore, the objective of this exploratory study is to enquire into the value and benefits of iterative design methodologies and user participation at the early stages of service design within a technology-driven pilot project.

\section{Literature review}

\subsection{On service design}

Service design was first presented as a new design discipline, by professors Michael Erlhoff and Brigit Mager, at the Köln International School of Design in 1991. Due to the newness of service design as a 
discipline, its definition varies across the academic literature, geographies and through time. Authors such as Zeithaml et al. (1990), Johnson et al. (2000), Mager (2004), Erl (2007), to Stickdorn and Schneider (2012), provide different perspectives on how to define the field. A compelling and simple definition is provided by the Design Council, which states that service design is "all about making the services we use usable, easy and desirable" (Design Council, 2007). More in detail, Mat Hunter (Hunter, 2015), Chief design officer of the Design Council, describes it as "the act of shaping service experiences so that it works for people. Both removing the lumps and bumps so that it is nice and easy to use but also adding a little bit of magic to make it compelling". Instead of concentrating on the product, service design focuses on what effect it will generate on the user, on the purpose that it will carry (Peffers et al., 2008). In this study, service design is defined as the tangible or intangible activity that seeks to improve the interaction between a service provider and its customers. This is done by generating experiences that meet the needs of the customers in an engaging, efficient and user-friendly way involving behaviours, communication and environment (Service Design Network; Hollins and Shinkins, 2006).

In one of the first books about service design, Service Design Thinking, Marc Stickdorn and Jakob Schneider (Stickdorn and Schneider, 2012) establish the five principles service design needs to include: (i) it needs to be user centred; (ii) it needs to be co-creative and include different people involved in the service somehow; (iii) service design needs to visualise the customer journey and the core moments in the sequence; (iv) it needs to generate evidence for users about the service so that they can easily understand its experience; and (v) it needs to be holistic because a service is embedded in the context so it needs to consider the entire experience associated with it. The user and its needs are at the centre of service design, resulting in diluting the line that separates the designer from the user experience researcher (Sanders and Stappers, 2008), and operations from marketing (Patricio et al., 2011). These blurs are exemplified in the array of services design methodologies that exist (Zimmerman et al., 2008; Engine, 2009; live/work, 2009; Designthinkers, 2009) that differ in number and names of stages, but "fundamentally they all share the same mindset" (Stickdorn and Schneider, 2012, p.126) and final usercentred goal.

\subsection{Involving users in service design}

The growth of service design and its particularities has introduced new tools and methodologies that can help address complex issues, such as participatory (Schuler and Namioka, 1993) and co-creation design (Sanders and Stappers, 2008) in which users are at the core of the service design creation, however, it is not only focused on users but it also includes internal teams, customers, consumers, users, designers, in other words, all kind of stakeholders (Steen et al., 2011). Participatory design can take place at the beginning of the project during the exploration phase, across the user research, during the design phase or even in marketing, sales, distribution and after-sales (Simonsen and Robertson, 2012). Since service design typically involves behavioural patterns it is rather critical for it to understand and tackle how they are threaded together (Holmlid, 2012).

In terms of the benefits that involving users in service design brings to the project, Table 1 shows how it includes both learnings in the research, improving the customer experience, as well as enables an empirical measurement of results achieved (Wilson et al., 1996, 1997; Kujala, 2003). In the case of technology driven service innovations, it is important the design methodology can help explore the relationships between companies and their customers (Johnson et al., 2000; Rayport and Jaworski, 2004) when currently customers do not play a key role. Many organisations still launch digital services without understanding customers experience needs and wants (Patricio et al., 2011). This has a negative impact on the results as technology driven approaches that are not user-driven tend to fail to deliver a successful user experience. Therefore, it is vital to measure the value of successful service design by measuring desirability, day-to-day relevance, likeability, from the user side, and viability and feasibility from the business side, which refers to being able to be offered by the business, and having the technical skill to deliver (Holthuis, 2011). Therefore, the research must embrace the perspectives not only of current and/or potential users, but also of the service providers and business stakeholders, referred as the "empathy triangle", which conforms the customer experience, which is an essential part of service design (Gould and Lewis, 1985; Hegeman, 2016). 
Table 1. Benefits of user participation in service design

\section{BENEFITS ON USER PARTICIPATION IN SERVICE DESIGN}

It empowers participants by perceiving their opinions are important
Helps to shape the research according to observed needs and wants
the progress and identify problems addressed
It enables a dynamic and structured way to gather useful feedback, monitor

In the case of the telecoms organisations, Mullins and Sutherland (1998) found that a best practice in this industry was to use prototypes to explore, understand the usage customers made and the benefits gained from new services. However, besides this study, it is rather difficult to find guidance in the literature on user involvement in service design in the telecoms industry (Magnusson et al., 2003) so it becomes necessary to generate more studies regarding the benefits of user involvement in this sector.

\subsection{Using the Double Diamond Process to tackle user participation in service design}

The Design Council (2007) proposes a model based on four stages (Discover, Define, Develop and Deliver), called the Double Diamond Process, due to the shape it follows (illustrated on Figure 1). However, when considering a design process to be followed by multidisciplinary teams of areas such as technology, innovation, design, cognitive engineers and data scientists, it is also important to take in account a statement provided by this same organization: "methods are not rigid protocols to be followed unthinkingly, but frameworks that can and should be adapted to the task at hand" (Design Council, 2007, p.6).

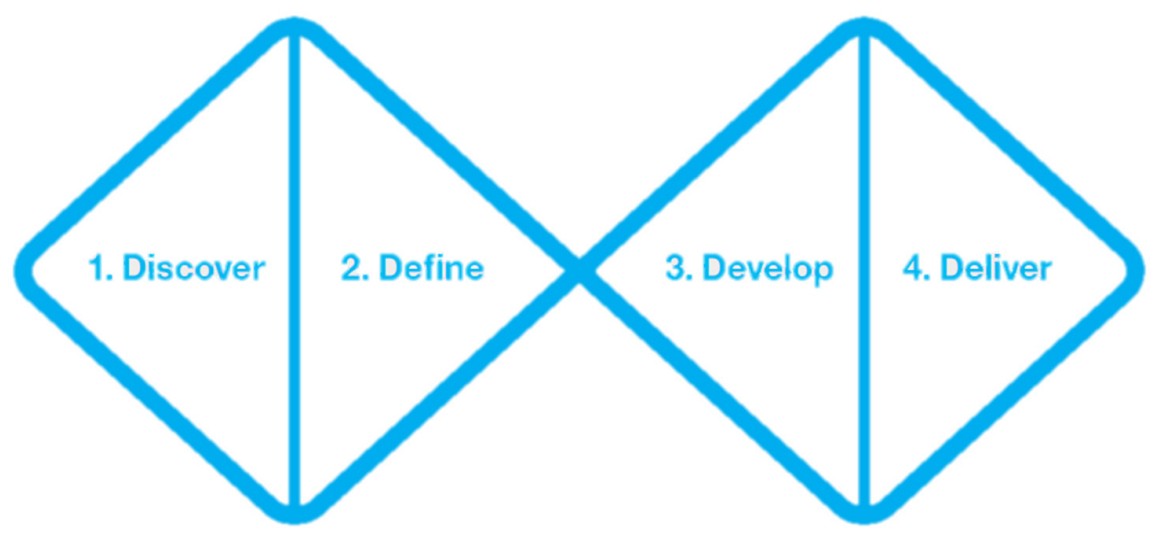

Figure 1. Design Council Double Diamond Model

Each of the Double Diamond Process phases carry on multiple methodologies that transform research into tangible outcomes (King, 2016), which in turn aid the service design to achieve what Jamin Hegeman (Hegeman, 2016), Head of Design for Financial Services at Capital One calls "co-value", which is providing service value both to the customer and to the business. However, when we are dealing 
with large and complex teams, which differ in backgrounds and methods, how does this work? How can value and successful outcomes be pursued as one team?

\section{Context of the pilot project}

Telefonica, a leading multinational telecommunications company founded in 1924 in Spain, and currently present in 21 countries with more than 346 million customers (trading as Movistar, O2 and Vivo), is developing an Artificial Intelligence (AI) based on cognitive capabilities, called Aura, to generate a new relationship model between the company and its customers. Nevertheless, they are not the only Telecoms service provider in the search of AI in the form of Data Driven Virtual Assistants. Along with the current digital transformation initiative of Telecom companies, came greater investments and research in AI and Virtual Assistants to define new relationship models with their digital customers (World Economic Forum, 2017). They are focusing on Artificial Intelligence to define new user experiences, such as personalized experiences, updates in real time and sensitive to the context in which users interact with the AI.

In the case of Telefonica, Aura will help users to manage their hired services in a more intuitive way, simplifying the processes, maximizing the use of the services and opening the door to a new user experience, all of this by voice interaction. The value proposition is strong and the reception of the concept has been incredibly positive for both the organization, media and analysts in industry. However, developing Artificial Intelligence is a complex task, even more if the objective is the generation of a cognitive intelligence that is able to acknowledge, understand, anticipate, foresee and answer accordingly to users. In the case of Telefonica, introducing Aura to the public for the first time was crucial in order not only to test the concept, but also to implicate user participation in service design to evaluate a simulated situation of interaction between real users and Aura, where the levels of uncertainty were still very high. Consequently, the pilot Meet Aura was created. However, a question arose, why a pilot?

Meet Aura's objective was to serve as a feasibility study for future similar activities, by evaluating strengths and weaknesses of the process, research activities and likely outcomes (Van Tejilingen and Hundley, 2002). This in return would generate a conceptual framework that could help to identify challenges that tend to emerge in practice (Tashakkori and Teddlie, 1998) in high uncertainty technology driven projects. Consequently, when establishing how to carry out Meet Aura Pilot and looking at current design methodologies, the team realized these did not match the complexity and high levels of uncertainty of the project. Therefore, it became crucial to generate an ad-hoc design methodology that helped to gather rich data in this type of technology-driven projects in order to improve breakthrough innovation services.

Moreover, the Meet Aura pilot would help the different multidisciplinary Telefonica teams to learn from the actual use and requests made to Aura to improve both the natural language recognition system and the user experience before its launch into the market, involving users to participate in the service design implementation to seek not only a higher chance of success but also of customer satisfaction.

\section{Methodology}

\subsection{Meet Aura pilot}

Meet Aura's pilot consisted on a phone booth cabin on a Telefonica's store in Madrid, which had available a tablet with Aura's AI incorporated so that users could test a variety of its AI functionalities. Some examples of its use cases were requesting a movie recommendation or searching for a series in Telefonica's catalogue depending on actor or genre, changing the channel of the TV placed in front of the cabin, between others.

The core characteristic of the Meet Aura methodology was its iterative nature, because the teams would be constantly monitoring the pilot and the user experience in order to implement its learning in real time with system changes, which would be then tested again by users, analysed by the researchers and improved once more by the cognitive team. This cycle would repeat itself throughout the pilot as shown in Figure 2. 


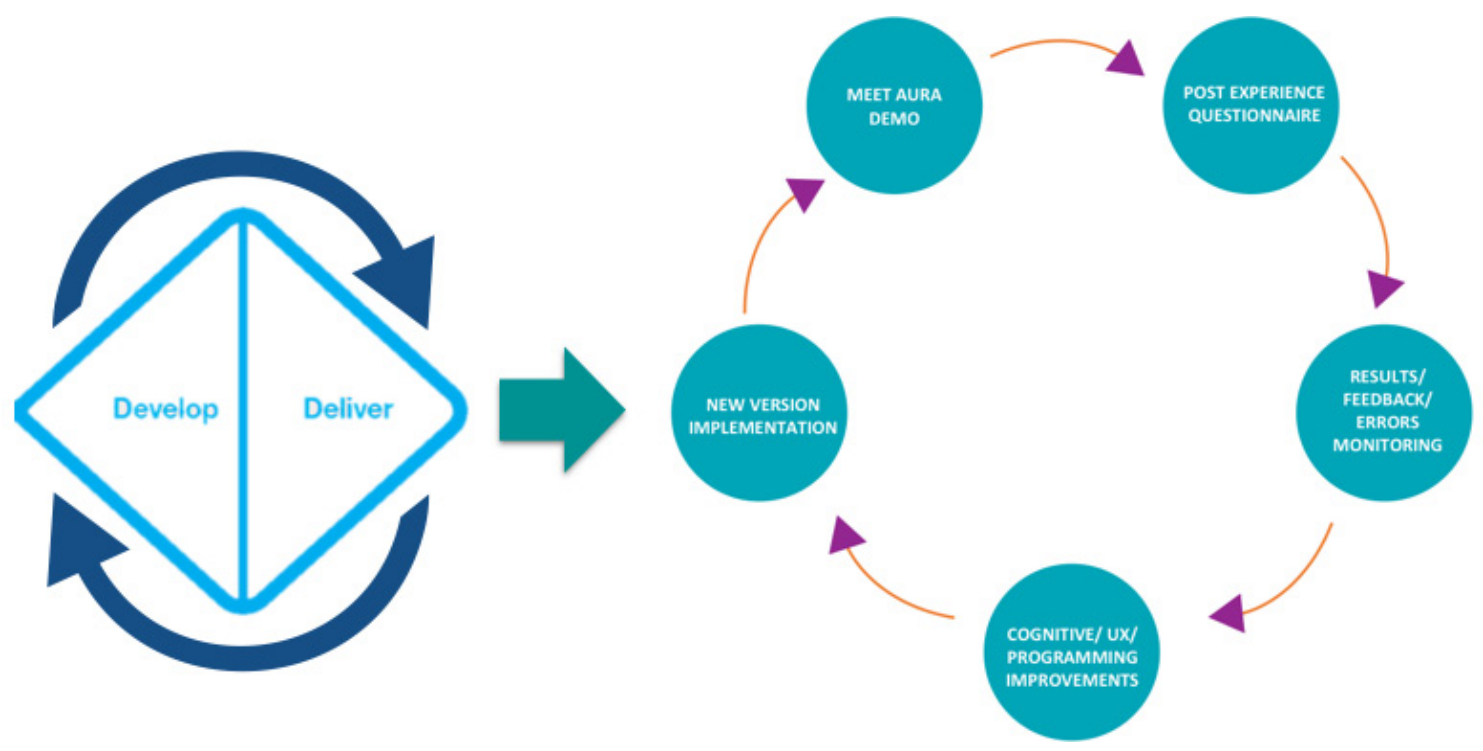

Figure 2. Iterative design methodology

This iterative process would then be replicating the last two phases of the Double Diamond Design Process (Design Council, 2007), for it would generate a functioning prototype (Develop) that could be tested (Deliver) and refined (Develop) repeatedly during the extent of the pilot. Similar principles are used in Lean Startup (Ries, 2011), which focuses as well on gathering users' feedback at very early stages in order to avoid wasting unnecessary resources (Mueller and Thoring, 2012), as well as to iterate results under the cycle build, measure and learn. In the case of this study, the reason for leaving behind the first two stages of the Double Diamond was the lack of necessity to look for inspiration and to define the challenge to address, as they had already been identified. What became essential was to make rapid and constant changes on problems detected through user interaction, so improvements could take place in order ameliorate the customer experience.

\subsection{Iterative versus stable phase}

Meet Aura pilot lasted ten weeks and was divided into two phases: the Iterative Phase, which took place the first 6 weeks, and the Stable Phase the following 4 weeks. The design methodology of constant feedback, its review, and system improvements was carried throughout the whole pilot, however the changes during the Iterative Phase were more plentiful for, as Figure 3 highlights, the key characteristic in this phase was introducing new use cases into Aura's system. The new cases introduced were more personalized functionalities such as requesting the user's Telefonica bill, watching their current uses of the services or asking for what products they had hired with the company. On the other hand, during phase two, the Stable Phase, no new use cases were added, therefore its name, so the teams would see the whole experience evaluation and focus more on improving the user experience. The differentiation between phases enabled a thorough understanding of the impact of the system improvements on the service experience for the users and the performance of Aura.

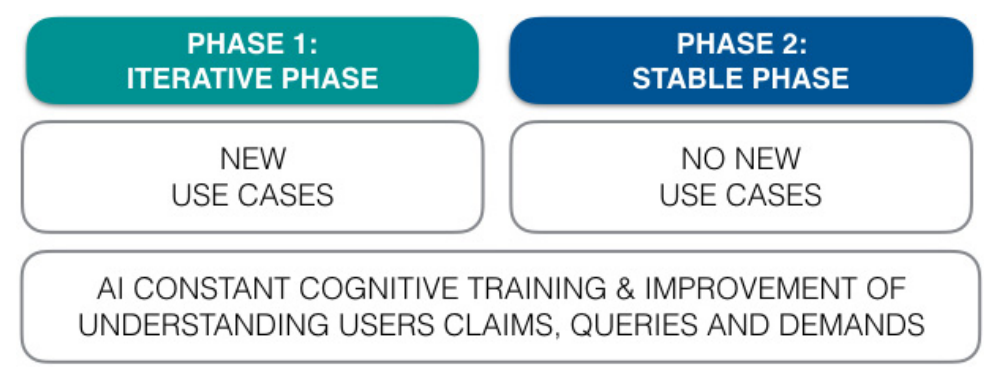

Figure 3. Pilot phases: Iterative and Stable 


\subsection{Design methods}

A triangulation strategy of multiple design methods was chosen to gather the quality feedback and monitor the pilot and the user experience during and after the user experience of Aura, therefore in the Deliver phase, to feed afterwards into the Develop phase. This strategy was considered as most appropriate for this pilot in order to compare and complement different sources of information to generate a holistic understanding of the users' experience and implement proper changes in Aura:

- A quantitative study to monitor internal metrics of Aura's system when customers went through Meet Aura's demo. Examples of these metrics were duration of the demo per user, used cases tried, different errors produced by the system, as well as a record of the requests made to Aura to identify what users said to Aura and what did the AI replied.

- An online questionnaire that users would complete after the demo so the team could evaluate their experience, perceptions and interest. The key benefit would be to understand how the user's experience was with the demo. By crossing the data between the internal systems monitoring and the online questionnaire, the team could thoroughly evaluate the feedback and refine the AI technology and experience accordingly.

- Non-participant observation of customers during the demo to understand the context, the barriers, pain points as well as learning the power of language and speech to capture pilot participants. This method was chosen as it seeks to deepen knowledge around behaviours and users' perceptions (Lindlof and Taylor, 2002).

- Weekly interviews with the demo facilitators as well as a final group interview to evaluate the meaning of their experience (Schwandt, 2000) during the evolution of the pilot and generate a series of key learnings that consider for future pilot studies.

In terms of numbers, at the end of the pilot project, 810 demos were carried out, 363 post-experience questionnaires were filled out, four full-day non-participatory observations took place and 10 interviews with the demo facilitators were conducted (Figure 4).

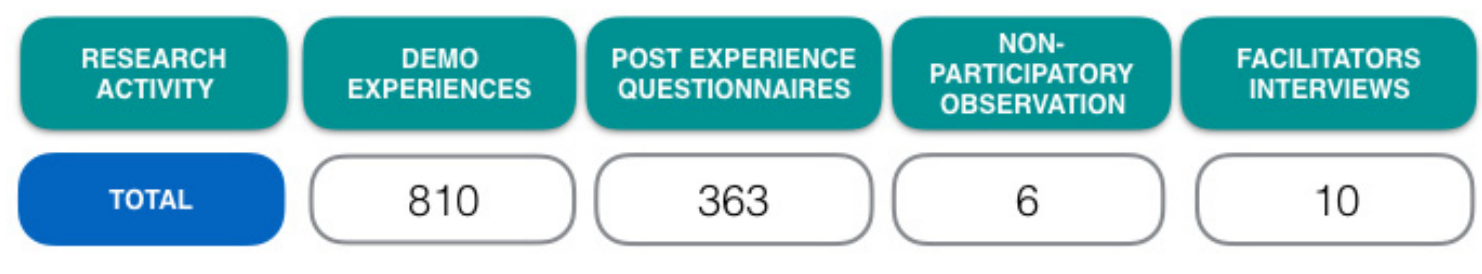

Figure 4. Total numbers design methods

Additionally, two full-time external facilitators were included in the team so they could attract users, guide them through the demo and carry out the post-experience questionnaires. The reason for doing so was to have first-hand information about: barriers, expectations, interaction and most importantly, to understand the context of the demo, the reasons why users gave the types of answers they did and to spot any errors that might come up in the demo, so the internal teams could sort them out as soon as possible.

\subsection{Building a conceptual framework for pilot projects}

As explained before, the main objective of Meet Aura pilot project was to learn, therefore the teams generated a conceptual research framework that would allow them to monitor and re-train Aura, and therefore, enhance the customer experience. At a user research level, the design methodology in the framework could enable the different teams to iterate results in order to keep improving Aura's system while making first contact with real users and test the improvements that were taking place.

Figure 5 illustrates the six phases that form the conceptual framework. They were chosen to help to identify weaknesses or errors in the performance of Aura's system, pass the message to the team in charged from UX, Technology and Cognitive, refine them, and test again. This way, feedback data would be gathered from both the users and the facilitators, in order to evaluate the impact of the changes and start the cycle again. 


\section{USER EXPERIENCE PILOT FRAMEWORK}

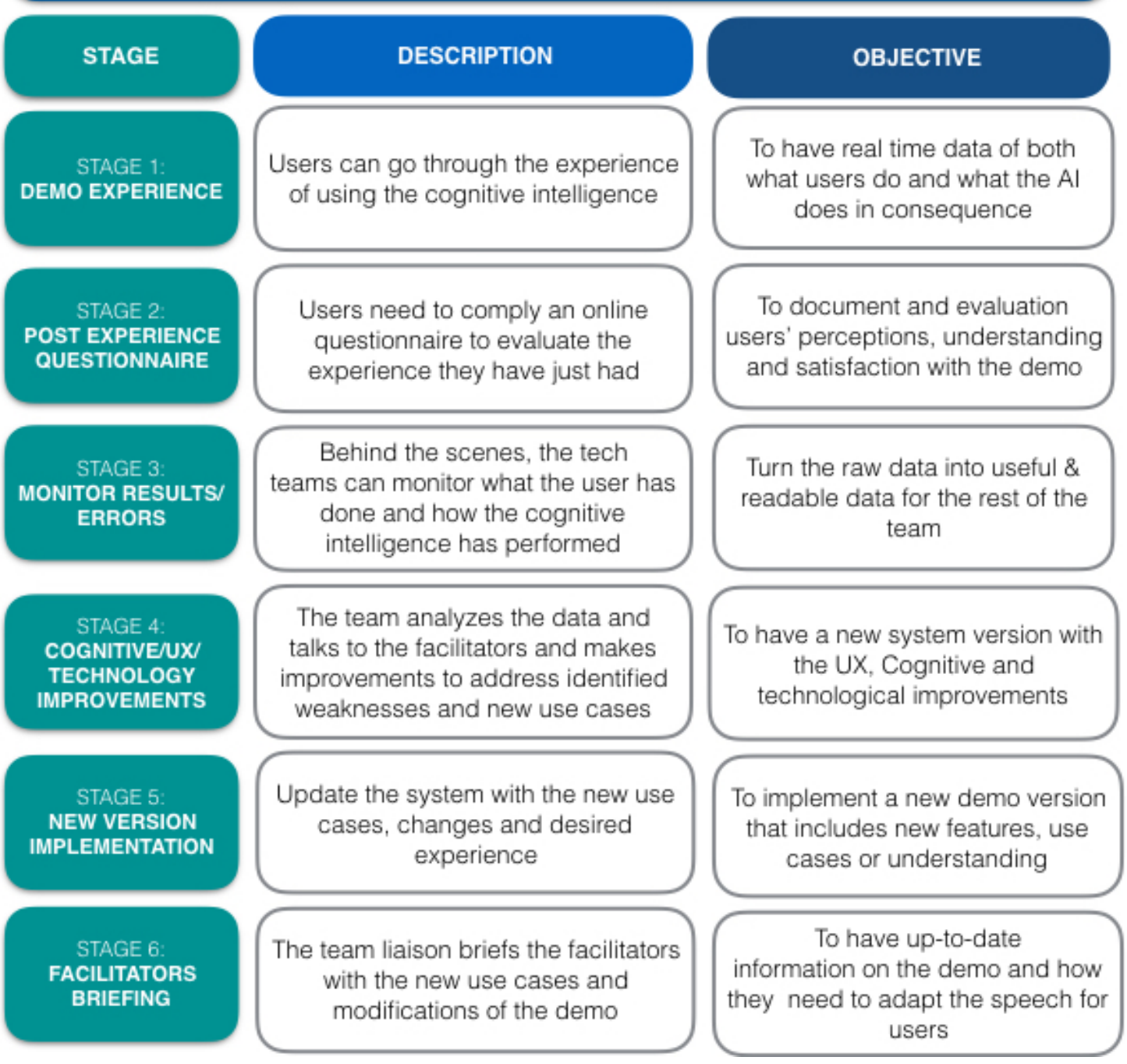

Figure 5. Conceptual framework for the Meet Aura pilot

\section{Findings}

\subsection{The benefits of iterative design methodologies in technology-driven service design}

At the beginning of the Meet Aura pilot the capacities of the AI were not fully developed, which represented an opportunity to establish how the methodology could potentially enhance the performance of both the technology, the facilitators role and the overall experience. Thanks to the length of the pilot, the monitoring and the interactions of real people, the AI system could identify users' expressions, that would be retrained by the cognitive team and, consequently, improve the next users' experience. In fact, the team managed to retrain 3495 new sentences from what users were telling Aura, improving the AI's natural language. This re-training made more fluent conversations possible, which is supported by the fact that there was an increase of user engagement (measured by the time they spent in the demo) and an improvement in the perceptions users had about Aura's performance as time passed and improvements were made. These results are shown in Figure 6, where it can be noted that users spent 63 additional seconds during the Stable Phase than in the Iterative Phase, which represents a significant enhancement considering the average time in the Iterative Phase. Moreover, users perceived the experience of Aura as simpler and friendlier in the second phase, increasing both an $8 \%$, and 
experimenting less frustration during the experience, which was selected as an attribute describing their experience by $5 \%$ less users of the Stable Phase than of the Iterative Phase.

Non-participant observation also contributed to identify and correct interaction problems with the tablet and with Aura, for instance when users had troubled with the microphone activation button, as there were different ways of activating it, either by a long press or by a single click. Non-participant observation enabled the team to observe the issue and implement both ways of interaction, therefore providing a better user experience, which on the long run provided a better evaluation of Aura and longer interaction with the demo. Consequently, the iterative methodology was shown useful for it showed that the constant learning by observation, the evaluation feedback and a better recognition of users' sentences actually did enriched the experience of Aura's service for its users.

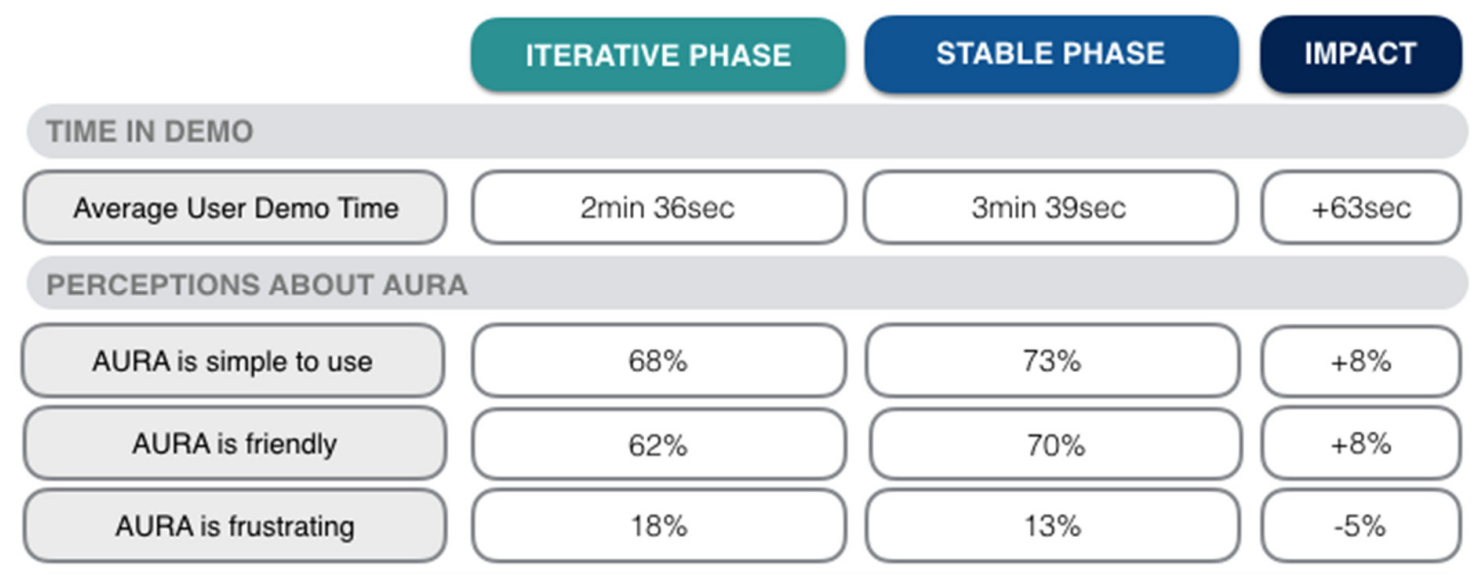

Figure 6. Compared time spent and perceptions

Splitting the pilot project into two phases, Iterative and Stable, helped to identify differences between the changes included in the Demo. The Iterative Phase focused on new use cases and its impact on users' post-experience questionnaire, which helped to understand their interest and relevancy in the overall experience. The Stable Phase was useful, instead, to evaluate the experience in relationship to alleviating pain points regarding voice recognition and to focusing on the expansion of new sentences. This combination represented an advantage to balance results about (1) the content of the demo and (2) the interaction between user and AI. In the case of this pilot project, the interaction between users and the AI by voice was key. By monitoring the conversations, teams behind the system could track on real time questions, answers, errors and everyday expressions the AI should learn to understand and answer accordingly. As the pilot progressed and these changes were made, the feedback from users regarding the voice interaction improved considerably. Figure 7 shows the results from the post-experience questionnaire on how the constant learning of the AI helped to improve users' experience around the voice interaction and how they experienced a more fluent conversation as the pilot evolved. In the second stage of the pilot, $6 \%$ more users agreed with the fact that Aura could follow a conversation than in the first stage, showing that changes that were done during the first part of the pilot had a positive effect on the experience of the Stable Phase users. The post-experience questionnaire helped to gather this information, as it was part of the user satisfaction and most liked aspects of the experience. This is one example of relevant information that could not be identified and explored solely by internal systems monitoring therefore showing that the triangulation strategy and multidisciplinary team work is fruitful. A challenge faced during the pilot was keeping the level of motivation in the facilitators. The weekly interviews with them helped the team to identify that dealing daily with users that reject participating in the demo was something that slowly affected the facilitators' enthusiasm. Several alternatives were considered (from changing the incentive scheme to increasing their rotation with new facilitators). If facilitators are not fully committed and motivated it becomes difficult for them to transmit the right message and engage users in the demo. This has a direct impact on the measurement and evaluation of user experience, as reflected in our analysis of both the monitoring and the post-experience questionnaire data. 


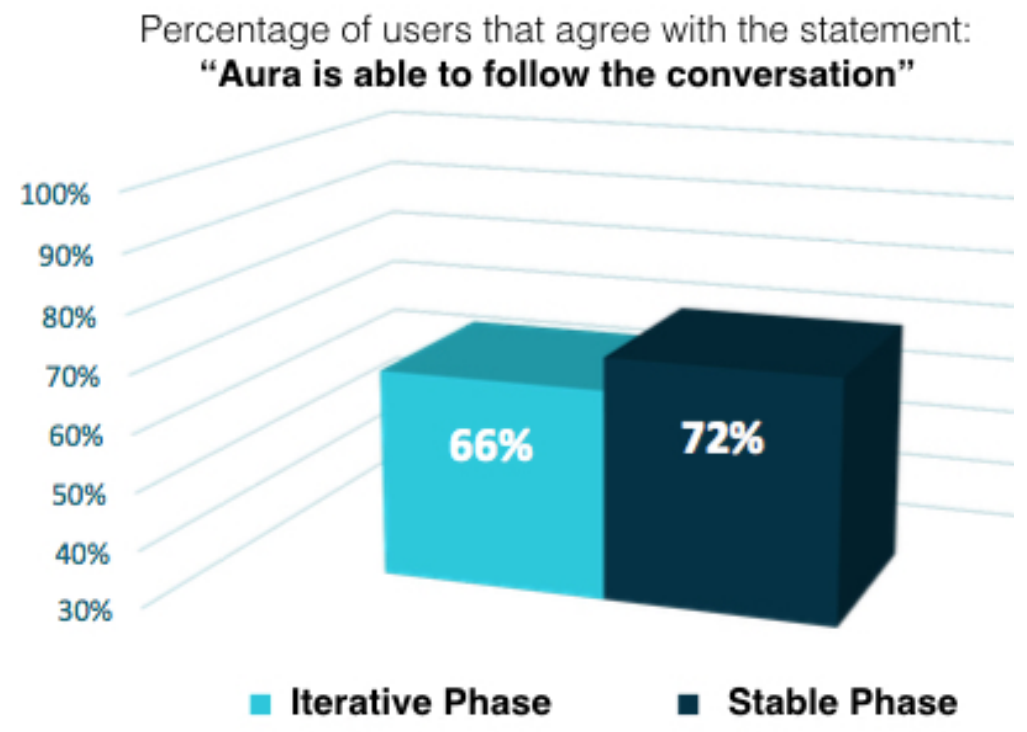

Figure 7. Improvement of voice interaction during Meet Aura pilot

The questionnaire also measured the Net Promotor Score (NPS) of Meet Aura. The NPS is a widelyused customer satisfaction evaluation system, where the user is asked if they would recommend the service experienced, and then the proportion of users reporting 1 through 6 in their recommendation level, called "Detractors", is subtracted from those reporting from 9 or 10, called "Promotors", providing a final Net Promoter Score (Reichheld, 2003). Results showed the level of recommendation of Meet Aura improved by 13pts in the second part of the Pilot, the Stable Phase, while neutrals decreased by in 19 pts, changes that were proven statistically significant by a T-Student test with $p$-value $<0.02$ and $<0.00$, respectively. Figure 8 shows the comparison between Iterative and Stable phase and the final result from both phases. Promoters of the Meet Aura experience increased across time, and on a general view of the pilot, ended up conforming almost half of the total number of participants. Once again it is exposed the benefits of the iterative methodology for the overall experience of the Aura users got better as the improvements on its system were being done, all based on their own feedback.

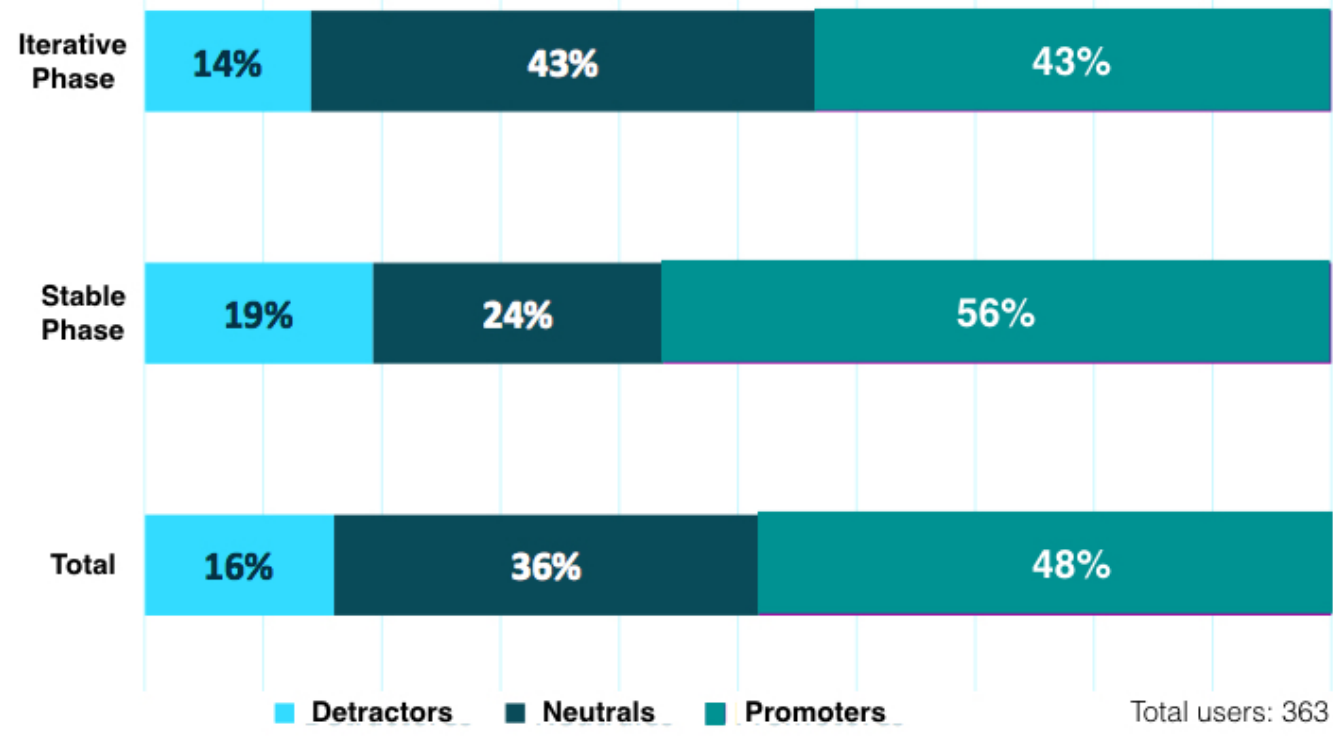

Figure 8. Meet Aura NPS 


\subsection{Working with multidisciplinary teams in iterative design methodologies}

Establishing the design methodology and design research methods that the project would follow helped the different team members to understand the benefits that were sought. However, bringing together teams from different disciplines is always a challenge as they have different business objectives, backgrounds and ways to of doing things. In the case of Meet Aura, as the pilot moved forward, the benefits of working under this iterative methodology and following a common conceptual framework became increasingly more evident. It helped teams at very different levels: they were faster, they learnt to appreciate the work of other teams, saw the value of putting design and UX at the core of the process and enabled the comprehension of putting the user at the centre of all that needed to be done, not just the technology that is being developed.

\section{Conclusions and key learnings}

Meet Aura pilot project helped the team to identify a series of key learnings from implementing an iterative design methodology as well as integrating users' participation in innovation services within a pilot project. The first key learning from this pilot project was how this dynamic way to gather users feedback, opinions and experiences from their active participation helped the different teams to identify problems, tackle the use cases in a different way, shape the demo, measure the progress and obtain empirical data to strengthen the pilot project results.

Secondly, having a well-defined methodology for the Meet Aura Pilot, such as the Conceptual Framework presented in Figure 5, helped internal teams to clarify which competencies, information and communication technologies were needed at each point of the process. This had a very positive impact on teamwork as every department involved was clear on the reasons why it was being done in that way and how collaboration played a key role in moving the pilot forward.

A third key learning from this study has been that the combination between monitoring of the data (what users where doing) and the post experience questionnaires (what users were perceiving) brought value in the form of an ongoing refinement to improve the service, the system and the experience (voice recognition, more relevant results, predictive behaviour, natural language learning, etc.). The postexperience questionnaire helped to identify WHAT was happening in the different demo experiences, making it easier to verbalise and reflect the users' opinion about the demo, while the monitoring made clearer the reasons WHY behind those answers.

Using an iterative methodology approach, which was based on the Design Council's Double Diamond model (2007), helped to maximize teams' capabilities, accelerate improvements and to keep both points of view in mind for teams (improve the system and seek users' feedback), which facilitated their collaboration and demonstrated a viable process to follow. This methodology has helped in everyday design work by generating a series of key learnings for other teams and projects on how to plan and develop a pilot project with high uncertainty and breakthrough innovation. In summary, this conceptual framework for Technology Driven Pilot Projects demonstrated it could maximize the interplay between design, innovation and technology.

\section{References}

Design Council (2007), Eleven Lessons: Managing Design in Eleven Global Companies: Desk Research Report. [online] Design Council. Available at: https://www.designcouncil.org.uk/sites/default/files/asset/document/ElevenLessons_Design_Council\%20\%2 82\%29.pdf (accessed 13.11.2017).

Erl, T. (2007), SOA Principles of Service Design, Prentice Hall, Boston.

Hegeman, J. (2016), Takeaways from the Service Design Network Conference 2016. [online] Available at: http://jamin.org/takeaways-from-the-service-design-network-conference-2016/ (accessed 14.11.2017).

Hollins, B. and Shinkins, S. (2006), Managing Service Operations: Design and Implementation, SAGE Publications Ltd. https://doi.org/10.4135/9781446214220

Holmlid, S. (2012), "Designing for Resourcefulness in Service: Some Assumptions and Consequences", In: Miettinen, S. and Valtonen, A. (Eds.), Service Design with Theory: Discussions on Change, Value and Methods, Lapland University Press, pp. 151-172.

Johnson, S., Menor, L., Roth, A. and Chase, R. (2000), "A critical evaluation of the new service development process: Integrating service innovation and service design”, In: Fitzsimmons, J. and Fitzsimmons, M. (Eds.), 
New Service Development: Creating memorable experiences, Sage Publications, Thousand Oaks, CA. https://doi.org/10.4135/978-1-4522-0556-4

King, O. (2016), Design-led change: Service Design Global Conference 2016 keynote. [online] Available at: https://www.youtube.com/watch?v=aquHnG-X2hI (accessed 11.11.2017).

Kujala, S. (2003), "User involvement: a review of the benefits and challenges", Behaviour \& Information Technology, Vol. 22 No. 1, pp. 1-16. https://doi.org/10.1080/01449290301782

Lindlof, T.R. and Taylor, B. (2002), Qualitative Communication Research Methods, Sage Publications, Thousand Oaks, CA.

Mager, B. (2004), Service design: A review, Köln International School of Design, Köln.

Magnusson, P.R., Matthing, J. and Kristensson, P. (2003), "Managing user involvement in service innovation: Experiments with innovating end users", Journal of Service Research, Vol. 6 No. 2, pp. 111-124. https://doi.org/10.1177/1094670503257028

Merholz, P., Wilkens, T., Schauer, B. and Verba, D. (2008), Subject to Change: Creating Great Products and Services for an Uncertain World, O’Reilly Media, Sebastopol, CA.

Mueller, R. and Thoring, K. (2012), "Design Thinking vs. Lean Startup: A comparison of two user-driven innovation strategies", Proceedings of the DMI 2012 International Research Conference, Design Management Institute, Boston, MA, August 8-9, 2012, pp. 151-161.

Patricio, L., Fisk, R., Falcao e Cunha, J. and Constantine, L. (2011), "Multilevel Service Design: From Customer Value Constellation to Service Experience Blueprinting”, Journal of Service Research, Vol. 14 No. 2, pp. 180200. https://doi.org/10.1177/1094670511401901

Peffers, K., Tuunanen, T., Rothenberger, M. and Chatterjee, S. (2008), “A Design Science Research Methodology for Information Systems Research”, Journal of Management Information Systems, Vol. 24 No. 3, pp. 45-77. https://doi.org/10.2753/MIS0742-1222240302

Rayport, J. and Jaworski, B. (2004), Best Face Forward. [online] Harvard Business Review. Available at: https://hbr.org/2004/12/best-face-forward (accessed 11.11.2017).

Reichheld, F.F. (2003), The One Number You Need. [online] Harvard Business Review. Available at: https://hbr.org/2003/12/the-one-number-you-need-to-grow (accessed 01.03.2018).

Ries, E. (2011), The Lean Startup: How Today's Entrepreneurs Use Continuous Innovation to Create Radically Successful Businesses, Crown Business, New York, NY.

Sanders, E. and Stappers, P. (2008), "Co-creation and the new landscapes of design", CoDesign, Vol. 4 No. 1, pp. 5-18. https://doi.org/10.1080/15710880701875068

Schuler, D. and Namioka, A. (1993), Participatory design: Principles and practices, CRC Press, Boca Raton, FL.

Schwandt, T. (2000), "Three epistemological stances for qualitative inquiry: Interpretivism, hermeneutics and social constructivism", In: Denzin, N. and Lincoln, Y. (Eds.), Handbook of Qualitative Research, Sage Publications, Thousand Oaks, CA, pp. 189-214.

Simonsen, J. and Robertson, T. (2012), Routledge international handbook of participatory design, Routledge, New York, NY. https://doi.org/10.4324/9780203108543

Steen, M., Manschot, M. and De Koning, N. (2011), "Benefits of co-design in service design projects", International Journal of Design, Vol. 5 No. 2, pp. 53-60.

Stickdorn, M. and Schneider, J. (2012), This is Service Design Thinking: Basics, Tools, Cases, Wiley, Hoboken, NJ.

Tashakkori, A. and Teddlie, C. (1998), Mixed Methodology: Combining Qualitative and Quantitative Approaches, Sage Publications, Thousand Oaks, CA.

Van Teijlingen, E. and Hundley, V. (2002), “The importance of pilot studies”, Nursing Standard, Vol. 16 No. 40 , pp. 33-6. https://doi.org/10.7748/ns2002.06.16.40.33.c3214

Wilson, A., Bekker, M., Johnson, H. and Johnson, P. (1996), "Costs and benefits of user involvement in design: Practitioners' views", People and Computers XI: Proceedings of HCI'96, Imperial College London, UK, August 20-23, 1996, pp. 221-240. https://doi.org/10.1007/978-1-4471-3588-3_15

Wilson, A., Bekker, M., Johnson, P. and Johnson, H. (1997), "Helping and hindering user involvement. A tale of everyday design", Proceedings of the ACM SIGCHI Conference on Human factors in computing systems (CHI'97), Atlanta, GA, March 22-27, 1997, pp. 178-185. https://doi.org/10.1145/258549.258699

World Economic Forum (2017), Digital Transformation Initiative Telecommunications Industry - January 2017 (White Paper). [online] World Economic Forum. Available at: http://reports.weforum.org/digitaltransformation/wp-content/blogs.dir/94/mp/files/pages/files/dti-telecommunications-industry-white-paper.pdf (accessed 01.03.218).

Zeithaml, V., Berry, L. and Parasuraman, A. (1990), Delivering quality service: Balancing customer perceptions and expectations, Free Press, New York, NY. 
Zimmerman, J., Forlizzi, J. and Evenson, S. (2007), "Research through design as a method for interaction design research in HCI", Proceedings of the SIGCHI Conference on Human Factors in Computing Systems (CHI '07), San Jose, CA, April 28-May 3, 2007, pp. 493-502. https://doi.org/10.1145/1240624.1240704

Dr. Marta Pérez García, UX Researcher

Telefónica I+D, CDO (Aura)

Ronda de la Comunicación, 28050 Madrid, Spain

Email: marta.perezgarcia@telefonica.com 